\title{
LUXIÉRNAGA
}

Nayeli Liliana Moreno Herrera 


\section{La vigencia del pensamiento de Simone de Beauvoir en torno a la vida de las mujeres}

\section{Introducción}

En nuestros días se vuelve normal seguir observando comportamientos negativos y con recriminaciones hacia al sexo femenino, se sigue viviendo con una cierta desvalorización de la mujer en la sociedad actual, lo cual no debería ser así, esto por supuesto es un problema con el que se ha tenido que luchar por muchos años, desde Simone de Beauvoir y su visión feminista se ha logrado identificar cuáles han sido las principales bases en las que se ha basado el sistema patriarcal, y en conjunto con ello se ha analizado para conocer de fondo cual o donde debería estar la solución para erradicar este problema, con esto se ha avanzado en gran medida para obtener una cierta libertad e independencia de la mujer. Es importante conocer las bases del feminismo, desde la primera ola y el giro que le dio la filósofa francesa de Beauvoir, pues además de integrar la lucha por los derechos y un estatus social que les permitiera participar activamente en sociedad que les pertenecía a todas las mujeres desde su nacimiento, se conoce y reflexiona como la mujer también ha tenido que dejar a un lado su miedo y el comportamiento indiferente o de resignación frente a todo lo que vivían cada una de ellas desde aspectos y clases sociales diferentes, es claro que las clases sociales también fueron y siguen siendo un aspecto que ha llevado a la mujer a la situación en la que se encuentra hoy en día, pues quienes han tenido un mayor acceso a la educación y conocer sobre el mismo feminismo las ha llevado a considerar su vida de otra forma y esto las ha ayudado a construirse y sobre todo a poner metas que las han conducido a pensar en una vida diferente, sin opresiones, desde su mismo sexo, hasta el sexo masculino. 
En el presente trabajo se busca demostrar la vigencia del pensamiento de Simone de Beauvoir, en torno a la vida de las mujeres que han decidió tener una independencia y de las mujeres que siguen sumergidas con las ideas y los valores morales que la sociedad ha impuesto para tener un control sobre ellas mismas. Las ideas específicas de una educación desigual entre niñas y niños, que los conduce a reproducir lo mismo de antes, las diferencias en aceptar la experiencia por hombres y mujeres durante su adolescencia o adultez, pues ambos casos caen en la misma conclusión y es la de quitarle a la mujer la posibilidad de que sea ella misma quien regule sus actos. En la actualidad es erróneo ver a mujeres que deciden actuar deliberadamente al intentar vivir una vida diferente y esto es lo primero que se debe de pensar y cambiar, aunque falta mucho por hacer, ya que la inseguridad juega otro papel muy importante dentro de este tema, pues varios de los actos de feminicidios se han desarrollado por la idea de un machismo radical, en las que el hombre no ha podio aceptar de alguna manera la libertad del sexo femenino. Las aportaciones de los textos que se han revisado para la elaboración de este trabajo han arrojado casi de alguna manera las conclusiones de que la mujer debe sentirse segura como principal aspecto, pues esto las llevara a deliberar y tener una definición concreta de lo que son y lo que serán y de forma consecuente se llegara a la trascendencia de la cual no ha hablado Simone de Beauvoir en su obra.

Desde la visión de López Pardina, encontramos una problemática que no se había mencionado como tal, de cierta forma la teoría feminista también estaba siendo desvalorizada desde su punto de vista, pues la filosofía estaba más preocupada por estudiar y analizar otras cuestiones de la sociedad que dejaban de lado a lo femenino, muestra como la mujer es desvalorizada desde un plano ontológico y social, pues las leyes y otras disciplinas parecían ser más necesarias que tratar de justificar de forma ideal la existencia del eterno femenino. Por otro lado, Aimé Tapia nos muestra las diferentes consideraciones en las que la mujer puede desarrollarse de manera plena, no siempre es cuestión de identificar a la mujer libre sin un hogar, sino que desde ahí 
mismo la mujer ha sido capaz de demostrar la destreza para poder convertirse en una mujer de familia y con el ideal se superación en un oficio o trabajo determinado. Femenias y Morant, nos muestran los caminos que ha sufrido el pensamiento de Beauvoir, de aceptación y rechazo de la sociedad por los aspectos que muestran la vida de una mujer, o de un hombre, desde lo físico hasta lo psicológico, se convierte en personaje lleno de controversias, pero también de reflexiones que han apoyada a una distinción de lo femenino dentro de una sociedad moral tradicionalista.

De manera breve se dan los puntos bibliográficos que crearon a una filosofa feminista como Simone de Beauvoir, desde sus mismas vivencias se convenció de la diferencia que tenían las mujeres en la vida, los puntos centrales de su pensamiento, como la ética, la responsabilidad y la filosofía de la libertad que apoyaban a las mujeres a una libertad. Conocer de forma breve la historia del feminismo desde las tres olas, para conocer las primeras luchas y la conformación de los ideales.

La metodóloga es hermenéutica, es una interpretación de la obra de Simone de Beauvoir, así como las aportaciones de otras feministas especialistas en el tema del feminismo en torno a esta filosofa francesa.

\section{Origen del feminismo: Simone de Beauvoir}

Simone Lucie Ernestine Marie Bertrand de Beauvoir nace el 9 de enero de 1908, proveniente de una sociedad burguesa rodeada en una educación moral cristiana. Sus padres fueron Georges Bertrand de Beauvoir, abogado, y Françoise Brasseur, quienes la apoyarán y aconsejarán desde pequeña. Su padre estuvo apegado a ella y la indujó a la literatura, lo que la llevó a encontrar escritos en los que se manifestaba la falta de pruebas para creer en un Dios y comienza a pensar que lo mejor es asumirse plenamente responsable de sus propias elecciones. Esto la estimuló a la edad de I4 años, según Elena Colombetti al atésmo.

Al poco tiempo su familia se ve afectada económicamente, por lo que decide entrar al instituto elitista y católico Adeline Desir para formarse como profesora, ahí 
hace amistad con Elizabeth Lacoina quien consideró como una de sus mejores amigas, con la que mantiene una relación muy cercana hasta su fallecimiento en I929. La muerte de su amiga, según Beauvoir, se debió a los problemas que tenía Elizabeth con su familia y en su matrimonio, ya que la opresión que ejercían ambos sobre ella afectaban en la toma de sus decisiones personales y fueron estos los que le generaron la meningitis mortal. Es a partir de esa experiencia que "comienza a preguntarse por el ambiente y estilo de vida de las mujeres en las relaciones con la sociedad, e incluso cómo se piensa a sí misma, lo que lleva o debe conducir a las mujeres a una identificación de lo que significa ser mujer".

Mientras se prepara y asiste a cursos para ingresar a la universidad La Sorbona conoce y se relaciona con distintas personas interesadas por el existencialismo, algunos de ellos amigos de Paul Sartre. En 1929, a los 2I años de edad, obtiene el título en Letras y la habilitación como profesora en filosofía, lo que la convirtió en la primera mujer en obtener estos títulos a tan corta edad. En esa época conoce a Jean Paul Sartre con quien comparte ideas existencialistas, lo que la unió a él en una relación intelectual y afectiva, pero sin compromiso legalmente formal, esto les permitió ser congruentes con las ideas existencialistas de la libertad.

En I93I comienza su carrera profesional como profesora en Marsella, luego en Rouen, y finalmente, a partir de 1936, en París en el Liceo Molière. En 1943 decide dedicarse a la escritura de su primera novela, La invitada, que llegó a ser una de las obras más conocidas y destacadas por la forma en que ella expone la vida y la relación que mantuvo con Sartre. En 1946 publicó su tercera novela Todos los hombres son mortales, la cual dedicó a Sartre y expresó la forma en cómo llevaron su relación hasta los últimos días de Sartre. Al término de la segunda guerra mundial escribe sus primeros ensayos filosóficos como ¿Para que la acción?, El existencialismo y sabiduría popular, además de Para una moral de la ambigüedad, en donde expresa en cada uno

\footnotetext{
1 Tinat, Karine, La biografia ilusoria de Simone de Beauvoir. Estudios Sociologicos, vol. XXVII, num. 81, septiembre-diciembre, pp. 755-800 El colegio de México, A.C. Distrito federal, México ISSN: 0185-4186. P. 763.ISSN: 0185-4186. P. 763.ico ISSN: 0185-4186. P. 763.
} 
de ellos su forma de ver y comparar la moral en los distintos ámbitos de la vida social, como es la misma libertad, la manera de ver al otro y la política. En la misma época, junto con algunos amigos que conoció en la universidad como Albert Camus, Maurice Merleau-Ponty y con Jean Paul Sartre, fundan para una editorial la revista Tiempos modernos que surge con la idea de que fuera el medio de expresión del pensamiento existencialista. El primer número sale a la venta el I5 de octubre de 1945, fue a partir de ahí que se convirtió en una revista muy importante para el ámbito político y cultural de Francia a la mitad del siglo XX por la forma en que estos temas llegaron a toda la sociedad.

En el año de 1949 se publica otra de sus obras más famosas, El segundo sexo, y en ella se encuentra una de las frases más célebres de su vida: La mujer no nace, se hace. Esta obra parte de la observación y el análisis que ella misma hizo, a través del estudio, de cómo la condición de la mujer era distinta a la de los varones desde milenios atrás, pues la mujer venía siendo considerada como un objeto, como lo otro, en esto se tenía que generar una conciencia de lucha individual y colectiva para lograr una independencia de libertad social ante la opresión existente que involucra a toda la comunidad femenina. Esto trajo consigo escándalo y revuelo en la sociedad francesa, pero, conjuntamente nuevas formas de pensar el sexo femenino, pues en la obra se realiza "un profundo análisis del rol femenino en las actividades cotidianas y la importancia de la mujer en la toma de las decisiones sociales, biológicas e intelectuales"2.

El segundo sexo se convierte en una de las bases más importantes para el desarrollo de diversos grupos feministas que buscan distintas finalidades con respecto al quehacer femenino. También fue una obra merecedora de diferentes investigaciones en varios países que ayudaron a crear una consciencia de la importancia de la mujer en la sociedad. Tinat, ha creído en estas ideas porque el feminismo a partir de conocer a De Beauvoir o de sus ideas contemporáneas se han reflejado nuevas luchas feministas

2 Ibidem, p. 776. 
en la sociedad. Gracias a las ideas aportadas en el trabajo de Beauvoir, mujeres de distintas sociedades pueden desarrollarse, en la actualidad, en distintos ámbitos sociales (educativos, laborales, políticos, culturales etc). Su obra le da fama y le permite realizar diversos viajes por el extranjero y estar atenta en la política internacional.

En I956 firma un manifiesto contra la invasión soviética a Hungría junto con otros intelectuales, debido a que en la guerra de Argelia se abre un segundo frente directamente hacia Francia y para apoyar a las dos naciones ella parte con la iniciativa de hacer el manifiesto en donde se exponía la forma de ayudar y lograr la independencia de Argelia, al mismo tiempo para favorecer a su nación, así ya no se vería participe en otra guerra, ese mismo año firma "El manifiesto de los $I 2 I$ en donde se muestra que el colonialismo es un sistema de opresión y que la guerra que se encuentra en curso es una independencia legitima por parte de los argelinos, a partir de ahí ya no podrían pelear por una invasión hacia ese país”3.

Una de sus últimas obras titulada la vejez se publica el 23 de enero de 1970. En ésta hace una reflexión y estudio del rol que cumplen las personas de la tercera edad, quienes son importantes porque siguen constituyendo y formando parte de la sociedad y no deberían verse como seres acabados, pues pueden seguir trascendiendo a partir de sus decisiones. Lo que muchas veces se piensa es que, por la edad, son incapaces de tomar decisiones y se les quita una parte importante de lo que aún es su vida; se les considera biológicamente viejos y socialmente obsoletos, esto provoca que ellos mismos se conciban así. Esta obra además de considerar importante a todo ser humano en vida, Colombetti ha mencionado que es una especie de denuncia social en la que se asume un gran compromiso con todos, de entender la libertad, la moral en todas las edades, pues a pesar del tiempo y de los años de Beauvoir pensaba que siempre estamos constituyéndonos, creándonos. En la misma década de I970 es cuando más se ve comprometida con la problemática social y la situación de la mujer y

${ }^{3}$ Colombetti, Elena. Phlosophica: Enciclopedia filosófica on line, biografías y vidas. 
se convierte en el símbolo contestatario y militante del movimiento feminista en unos momentos cruciales de acontecimientos históricos y culturales de la vida cotidiana de Francia. También se posicionó a favor del aborto ya que en su época era visto como un homicidio por parte de las mujeres si se decidía antes de engendrar como cuando ya se hacía la práctica, esto no permitía que la mujer tuviera un control individual de su reproducción. En 1972 publica Memorias de una joven formal en donde cierra sus volúmenes autobiográficos. En esta obra expresa lo que fue desde que era niña, de cómo vivió su adolescencia, ya posteriormente se publica La plenitud de la vida.

En 1980 muere su compañero de vida Jean Paul Sartre, situación que la lleva un año después a publicar el escrito de su obra titulada La ceremonia del adiós, en donde relata los últimos días de compañía junto a Sartre. Seis años más tarde Simone de Beauvoir muere el I4 de abril de 1986 en París por una neumonía. Sus restos hoy descansan al lado de los de Sartre, en el cementerio de Montparnasse.

Simone de Beauvoir fue reconocida como la filósofa francesa que destacó su trabajo existencialista aplicado a la reivindicación del derecho de las mujeres en su época y hasta la actualidad.

\section{Ideas centrales del feminismo de Simone de Beauvoir}

El feminismo ha sido el tema por el cual Simone de Beauvoir es reconocida, y es a partir de ella que se comienza un nuevo pensamiento frente al feminismo de la tercera ola que ya se venía formando, pues logra entender una nueva emancipación de la mujer analizando cómo se debe obtener una reflexión de lo que es ser mujer desde su nacimiento, y conforme pasa el tiempo, la mujer debe comenzar a tomar sus propias decisiones, a ser consciente de ella misma.

Su principal pensamiento se presenta como una filosofía de la libertad y el compromiso, en donde la cuestión ética es muy importante en todo momento. El primer pensamiento de Beauvoir existencialista inicia en la libertad y en identificar el límite de la propia trascendencia, que se autodefine con cada nuevo proyecto, la 
coexistencia entre diversas libertades que tenemos al relacionarnos con los otros y el mundo. Para ella el sujeto no puede considerarse acabado, ya que cada situación te pone en un contexto distinto que te hace aprender $y$, sobre todo, comprender el mundo, pues con base a ello, el cuerpo se vuelve el boceto de nuestro proyecto, a partir de ello se va constituyendo de lo que se va viviendo como individuo. En este mismo pensamiento podemos poner como ejemplo la creencia en ella de que no existían valores universales, pues cada individuo de manera subjetiva era capaz de ir identificando cuales serían más importantes en el trayecto de su vida, así es como la libertad que cada uno de nosotros tenemos en decidir lo que mejor nos parezca, como dice Colombetti, "La fuente de los valores no es el hombre impersonal, universal, sino la pluralidad de los hombres concretos, que se proyectan hacia sus propios fines a partir de situaciones cuya particularidad es tan radical e irreducible como la misma subjetividad"4, ¿Que nos queda pensar con esta idea?, que cada uno de nosotros nos vamos definiendo conforme pasa el tiempo y los fines que nos vamos proponiendo para cumplir y llegar a una meta específica, que es diferente en todos los individuos, nos lleva a comprender los valores de una manera distinta, además de justificar las acciones que hacemos conforme lo que creemos. Todos en nuestro pensamiento debemos proponernos fines o tareas que no deban ser vistos de esa manera, sino que todo lo que hagas resulte satisfactorio para tu persona y esto te motive a proponer nuevos fines que nos permitan trascender en la vida para crear nuestra propia moral realista.

Esa libertad que ella concibe es donde se quiere la libertad del otro, no podemos imponer en nuestras relaciones sociales ya sea de trabajo, familia y emotivas una serie de conductas que nos resulten agradables a nosotros, Simone de Beauvoir menciono que no se puede regular las acciones y el comportamiento del otro porque es como quitar tu propia libertad. La libertad está dividida en la ontológica y la moral, la primera hace referencia al sitio en donde el individuo es capaz de idealizar su

\footnotetext{
${ }^{4}$ Clombetti, Elena. Philosophica: Enciclopedia filosofica on line, Biografias y vidas.
} 
libertad sin pensar en la sociedad. Primero debe deliberar una interioridad que le permita saber cómo actuar y encontrar una identidad personal, que lo lleve a sentirse verdaderamente libre y auténtico frente a los demás; en la libertad moral se debe siempre reconocer un fin en donde no sea oprimida otra persona.

Se necesita querer ser libre y luego que los demás lo sean también, para estar en constante relación e interacción con el mundo, así todos lograrán ser competentes para entender de lo que uno es capaz de hacer para entender la propia libertad. Esto no significa que puedas hacer cualquier cosa, sino que superes lo que ya está dado para poder entender lo que es la libertad y así entender cómo se puede dar la propia existencia. El ser sólo puede examinarse cuando se enfrenta a libertades extrañas y distintas a las nuestras, porque nos permite reconocer que somos individuos totalmente distintos a todos los demás, cada uno de nosotros nos vamos autodefiniendo con las vivencias y decisiones que tomamos, a lo largo de la vida, pues vamos asumiendo qué posturas tomar frente a una sociedad con valores y saliendo a experimentar lo que es bueno y malo, para cada uno de nosotros.

En el segundo sexo expresa más ampliamente la idea de libertad de los otros, porque para de Beauvoir las relaciones humanas consisten en no quitar la libertad para poder proyectarse, para hacer de las personas una especie de objeto en determinados momentos que ayuda a deliberar tu propia existencia. Esta obra es dividida en dos libros, «los hechos y los mitos» y «la experiencia vivida». En el primero se expone una reconstrucción fenomenológica de lo que ha venido siendo la mujer desde la cultura y pensamientos pasados; en el segundo la experiencia vivida, nos habla de la mujer en sus diferentes fases de vida, madre, casada, lesbiana, prostituta; y entre las justificaciones, la perspectiva de la mujer narcisista, de la enamorada, de la mística, y al final nos habla de la mujer independiente, pero en todas estas formas de vivir diferente el sentido femenino recae la forma biológica que muchas veces vuelve a la mujer prisionera de su mismo cuerpo, pues expone como desde la más tierna infancia, la mujer experimenta su cuerpo como una cosa que tiene que proteger, atenta siempre a 
que sus movimientos no entren en contradicción con la feminidad que se espera que proyecte en todo momento. Se enseña que la mujer es quien debe ser más sentimental que el varón, queriendo comparar la vida afectiva con la fuerza física que sabemos en los hombres es mayor. Es correcto mencionar que al elaborar esta obra no quería reconstruir un feminismo radical, sino poner a la mujer en perspectiva de su misma reflexión, en reflexión del hombre también, donde comenzara a dejar el pensamiento de que el hombre es el único portador de vida. Para la existencia de la vida se necesitan los dos, mujer y hombre.

La política se vuelve otro de los temas que le interesa estudiar, quizás porque en el transcurso de su vida se vivieron las dos guerras mundiales que dejaron devastada la sociedad francesa. El estar cerca de firmas de manifiestos en contra de las invasiones le hizo creer que la política y la moral están demasiado unidas, porque todas las decisiones que se toman en ésta tienen que estar cargadas de valores y fines que ayuden a una sociedad a seguir adelante y siempre estar mejorándose. Aunque la guerra pasó en otra época, se considera que el sufrimiento y castigo que se generó hacia algunas personas era para lograr el triunfo, aun así, no se consideró ni la libertad ni los valores que habían formado a la persona. En otro aspecto también logra consolidar a la política como una ciudadanía en la que sólo los varones podían decidir, ya que el sexo femenino era débil como para estar al frente de la sociedad. En este aspecto también entra en la discusión si es correcto que desde la antigüedad los hombres sean los que han decidido cómo se desarrollará la historia misma, pues en sus manos estaba el elaborar diversas leyes que sólo eran beneficiosas para ellos, e incluso que desde la concepción se le haya considerado inferior intelectualmente a la mujer, para no poder estar frente a organizaciones importantes.

Aunque muchas veces se le quiere atribuir un pensamiento parecido al de Sartre ella también tiene propuestas originales en cuestiones éticas, que mayormente las fundamentaba con una ontología existencialista, en donde recalcaba la máxima importancia de tener libertad para actuar conforme los valores individualistas que cada 
uno vamos concibiendo. Otros de los temas en los que estaba interesada son la alteridad y el de la mala fe, pues es a partir de ellos que se ha venido desarrollando un pensamiento de inferioridad y, sobre todo, de no querer hacer o desarrollar buenas acciones que permitan un amplio desarrollo en sociedad, así como en la relación entre la existencia del individuo y las condiciones sociales, pues frente a estas dos se va conociendo la finalidad de la esa existencia.

En particular Simone de Beauvoir quería mostrar como una mujer debería proponerse a formarse desde sus experiencias individuales, pues desde niñas las formas de relacionarse con las familias indican lo que en un futuro se deseara en la existencia, es como ir constituyéndose de poco a poco, pues desde la infancia las formas de vida dentro de la sociedad indican los estereotipos que la sociedad exige, pero se comienza a crear una conciencia propia. La liberación ha sido lo que las conduce hacia la independencia, lo que las deja tomar una trascendencia, en donde actuarían y serían responsable de las mismas decisiones tomadas, aunque sea difícil situarse en el lugar que le permitirá eso, pues aún en nuestros días, en la sociedad, la independencia y la libertad de una mujer es muy cuestionada, pero es de vital autorreflexión para conocer y entender las posibilidades que la llevaran a situarse en el lugar en donde ella se sienta completa, aspecto que comprende todas sus partes como la satisfacción de cumplir metas y sentirse feliz de los que se ha logrado.

\section{Las olas feministas}

Todas las opiniones merecen ser escuchadas, pero éstas deben estar justificadas y fundamentadas por buena información. Muchas de las veces buscamos dialogar y opinar de cualquier tema sin conocer a fondo de lo que se habla con respecto a ello, lo que nos lleva a presentar una persona carente de información que solo busca defender un punto de vista mal fundamentado. Ahora pensemos, cuál ha sido el tema en la actualidad que ha provocado disturbios, actos de violencia tanto físicos como de lenguaje, en defensa de los derechos y el cumplimiento de leyes para el sexo femenino. 
Sí, el feminismo se ha vuelto el tema del que muchos hablan, unos en contra, otros a favor, pero lo primero que deberíamos de comenzar a trabajar es conocer, entender el origen y la finalidad por la cual se ha luchado para tener un feminismo en nuestra sociedad, pues la mayoría de las veces se están catalogando actos feministas sin ser así en realidad. Entonces lo principal es comenzar por conocer la historia del feminismo que se va desarrollando a partir de tres etapas importantes que hacen posible la actuación de la mujer en los diversos aspectos de la vida social y laboral.

El surgimiento de las primeras ideas de una inclusión en sociedad para la mujer, a una vida libre de prejuicios para ellas, se da en la época de la ilustración entre los siglos XVII y XVIII en Europa y es conocida como la primera ola feminista. Esta ola mejor conocida como el feminismo ilustrado y la revolución francesa nace como su nombre lo dice en el inicio de la revolución francesa "lo que se buscaba como objetivo en ese momento fue las libertades, los derechos y la igualdad jurídica que, en ningún aspecto consideró a la mujer”" Entonces la lucha comienza de forma colectiva por el reclamo de la subordinación en la cual se encontraba el papel de la mujer en sociedad, se inició por pensar cuál sería el primer paso que permitiría terminar con esta manera de ver a la mujer como un individuo que esta creado para el hogar y ser madre, por lo cual se pensó que la clave para superar la subordinación a la que estaba sumergido la ge a la que estaba sumergido el género femenino era el acceso a la educación. Mientras se efectuaba esta revolución se seguía creyendo que las mujeres eran una especie de ayudantes para los ciudadanos que solo eran considerados los hombres.

Olimpia de Gouges denunció en la Declaración de los derechos de la mujer y de la ciudadana (197I), todo lo que había ganado la revolución, pero olvidándose de la mujer, se requería a la mujer libre, con derecho al voto y sobre todo el acceso a la educación, De las Heras menciona en este sentido que, a pesar de las luchas, la

\footnotetext{
${ }^{5}$ De las Heras, Aguilera, “Una aproximación a las teorias feministas en universitas". en Revista de filosofía, derecho y política. Año, número 9, p. 48.
} 
actuación de la mujer en sociedad aún era mal vista. Los objetivos principales en esta primera fase y que solo tuvo éxito fue la entrada a las instituciones educativas.

Una segunda etapa de las ideas feministas se da lugar en XIX y XX conocida como la ola del movimiento sufragista que buscaba voz y voto en la ciudadanía, durante este tiempo se crea el partido laborista independiente, la unión social y política de las mujeres. Con esto se logró que en los países occidentales se diera el derecho al voto a la mujer. En Estados Unidos las mujeres, al igual que los hombres, participaron en lucha de la independencia del país, a partir de ahí en I848 se aprobó la declaración de Seneca Falls en la que "se plasmaron doce decisiones en las cuales está la exigencia para alcanzar la ciudadanía civil y la modificación de principios a costumbres y moral"'. Ya con el acceso a la educación y la gran formación académica que se iba desarrollando en algunas mujeres impidió que se les negaran algunos de sus derechos, pues poco a poco ellas se iban convirtiendo en conocedoras de lo que era su existencia en la vida social. Además de tener una amplia participación en las guerras de independencia que las posiciono en actividades laborales que se pensaban eran exclusivas para hombres, como la metalurgia entre otras. Las sufragistas inglesas consiguieron tener como aliado a John Stuart Mill, que presentó la primera petición a favor del voto femenino en el Parlamento y que gracias a ello fue una referencia para pensar la ciudadanía no excluyente, a partir de ahí se comenzó la lucha más profunda para erradicar la subordinación y generar la emancipación de todas.

Tras la formación de la segunda guerra mundial, tanto el gobierno como los medios de comunicación exponían y deliberaban que lo mejor; y el objetivo primordial era que las mujeres se alejaran de la producción laboral y nuevamente se integraran a la idea de permanecer en el hogar como lo habían hecho durante mucho tiempo, lo cual no ocurrió por la llegada de la obra de Simone de Beauvoir la cual produjo rápidamente un pensamiento del sexo femenino como la otra cara del espejo del sexo masculino, la idea central es la libertad, en todo aspecto de las mujeres,

\footnotetext{
${ }^{6}$ Ibidem, p. 50.
} 
buscaba construir una teoría en la que se analizara y explicara la subordinación de las mujeres, De las Heras entendía que de Beauvoir trataba de hacer una trascendencia y una introspección de la mujer desde la misma mujer, ¿Qué significa ser mujer?, somos una construcción social que solo se ha desarrollado por hombres, lo cual ha excluido a la mujer en muchos aspectos diría la filósofa Simone de Beauvoir.

Alrededor del año 1970 surge el feminismo contemporáneo en donde se comienza a tomar, de una forma más radical y reacomodando una escala de valores para la detención de la opresión del patriarcado, un nuevo concepto para la historia del feminismo.

La mística de la feminidad (1963) una obra de Betty Friedan aparece en Norteamérica en 1963, en donde su autora expresa que el problema de las mujeres era que estaban experimentando un vacío al saberse definidas por las distintas situaciones y funciones que las colocaban las sociedades enteras (esposa, madre, ama de casa), y para liberarse de esta trampa de la mística de la feminidad tenían que lograr una propia autonomía incorporándose al mundo del trabajo. De la Heras menciona que en I966 creó la organización nacional de las mujeres, en la que, además de ser la más influyente, representaba el feminismo liberal, en ello se fomentaba que si la mujer tenía espacios para trabajar dentro de la vida laboral y política estos tendrían soluciones. Las liberales comenzaron definiendo el problema de las mujeres como su exclusión de la esfera pública, propugnando de esta forma su inclusión en el mercado laboral y terminaron abrazando la tesis de lo personal es político. Enseguida de esta postura se desarrolla el feminismo radical, quien protagonizó la década de los sesenta y setenta.

Este feminismo radical comienza con el movimiento de liberación de la mujer, en donde concordaban con la necesidad de separarse del hombre y distanciarse del feminismo liberal, desarrollándose entre 1967 y 1975. Dos obras fueron fundamentales durante este tiempo, La política sexual de Kate Millet y La dialéctica de la sexualidad de Sulamit Firestone, en las cuales se formularon e integraron el 
análisis de patriarcado, género y casta sexual, pues desde un enfoque distinto mostraron como la sexualidad es el parteaguas de una diferencia entre mujeres y hombre, desde la opinión de Barba Pan. El patriarcado se define como el sistema básico de dominación sobre el que se levanta el resto de las dominaciones, como la de clase y raza. El género expresa la construcción social de la feminidad y la casta sexual alude a la común experiencia de opresión vivida por todas las mujeres.

El feminismo cultural exalta el "principio femenino" y sus valores. Se autoproclama defensor de la diferencia sexual, de ahí su designación como feminismos de la diferencia frente a los autoritarios, se condena la heterosexualidad y se acude al lesbianismo como única alternativa de no contaminación.

El feminismo después de los ochenta se venía dirigiendo entre dos vertientes, pues en unos países se buscaba crear organismos de igualdad para lograr un feminismo conservador, mientras que en otros países se reclamaba el sistema de cuotas y la paridad por medio de discriminación pasiva, debido a que existía todavía privilegio en las manos masculinas tanto en escalas jerárquicas como organizacionales, este organismo se convirtió rápidamente en el objetivo de lucha, lo cual llevo a la mujer a tener presencia y visibilidad en todos los ámbitos públicos. Posteriormente se crearon grupos pequeños e informales en donde las mujeres intercambiaban e informaban de distintas experiencias que servían para llegar a una concienciación de lo que vivían, luego fueron programas en los que se apoyaba a la mujer por organismos estatales que, aun en nuestros días, siguen funcionando.

El feminismo, para esta época, se divide en tres perspectivas: feminismo liberal, socialista y radical, además de feminismo cultural, de la diferencia y postmodernista. La profesora María Leonor Suárez Llano, especialista en filosofía del derecho clasifica las propuestas feministas en dos categorías, la primera es el feminismo domesticado que pretende extender las categorías de análisis y definición masculinas de las mujeres donde los dos poseen el mismo estatus; la segunda el feminismo idómito porque 
reclama la quiebra del entramado político-social, científico, ontológico y epistemológico del sistema patriarcal.

Actualmente existe un debate en el que se discute si se podría hablar del feminismo o de los feminismos, lo cierto es que, si resulta difícil comprender la categorización del feminismo en corrientes o teorías, podemos identificar que todos engloban elementos y objetivos comunes que comparten para lograr su finalidad última. Las propuestas feministas parten del análisis de la situación de la mujer frente a la sociedad y la denuncia de relaciones de dominación del sexo masculino hacia el femenino; además de considerar la organización social dominada por el patriarcado que se basa en las diferencias de género, y que ha tenido como resultado un proceso histórico social y no un hecho natural.

\section{El pensamiento revolucionario de Beauvoir en torno al feminismo: El segundo sexo}

Aunque ha pasado mucho tiempo de la publicación de la obra El segundo sexo sabemos que, hoy en día, vuelve a ser necesario conocer sobre el tema del feminismo, ya que en la actualidad con la diversificación de este mismo se han propiciado distintas problemáticas y sobre todo que la palabra feminismo remita a muchas personas a pensar en protestas y marchas, es por esto que la autora menciona "el hecho de que se siga polemizando sobre su obra es la prueba palpable de la actualidad de su pensamiento"', porque sigue siendo un problema social actual, el cual nos involucra a todos.

La obra El segundo sexo, se pública en el año de I949 en dos tomos, el primero Los hechos y los mitos y el segundo La experiencia vivida. En ambos de Beauvoir hizo una construcción de lo que conlleva ser mujer. En el primero analiza lo que se dice acerca de las mujeres, desde lo biológico hasta lo mitológico. Expone la manera en que han contribuido estas versiones en la reconstrucción social que une

\footnotetext{
7 Cid López, Rosa María. (2009). Simone de Beauvoir y la historia de las mujeres. Investigaciones Feministas, Universidad de Oviedo, p. 66.
} 
todas ellas para decir qué es la mujer. El elemento común es la mujer siempre debe actuar pasivamente, callar y aceptar lo que la sociedad patriarcal dice que es lo femeninamente correcto e incorrecto. En el segundo tomo, analiza de manera más cercana la vida de la mujer, pues haciendo una especie de narración de las experiencias de la infancia, adolescencia femenina introduce en la forma tan distinta que se vive en cada una de ellas, pues en cada una de las etapas se sufren cambios hormonales y físicos, además de que cada una va aceptando su realidad o la va queriendo cambiar, propone la construcción de un nuevo paradigma de lo que debe ser la mujer a partir de un reconocimiento de su capacidad de autosuficiencia, en el que para realizar esto "debe ser la mujer la primera que debe pensar que es capaz de desarrollar su vida de manera libre, cuestionándose y actuando conforme sea correcto para llegar a ser la

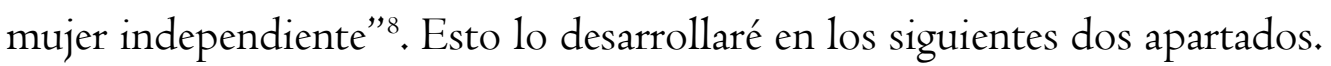

\section{La mujer en los hechos y los mitos}

Simone de Beauvoir analiza la situación de la mujer en distintos ámbitos y aspectos de la vida social, biológico, histórico, mitológico, y en cada uno de ellos se presenta a la mujer como un ser que necesita trascender. Esto lo puede conseguir a partir de la toma de decisiones individuales que le permitan desarrollar su vida al igual que la del hombre. Beauvoir incita a las mujeres a que comiencen a tomar el papel de protagonistas en la vida, de iniciar a sentirse dueñas de sí mismas, y que no sean los hombres los que las definan. Reflexiona y expone la manera en que la mayor parte del pensamiento masculino dirigido hacia la mujer, hace referencia a que es un ser irracional incapaz de poder decidir sobre su misma vida, que estaba creada y dotada para que alguien más, ya sea padres, hermanos o marido la acompañaran y fueran ellos quienes tomaran las decisiones más importantes de su vida, lo que no permitía en ningún momento que las mujeres se constituyeran como seres individuales, que

${ }^{8}$ De Beauvoir, Simone. (1949). El segundo sexo, Alianza, México, p. 55. 
pudieran administrar sus bienes y, sobre todo, expresar sus más profundos sentimientos.

La mujer, de acuerdo con Beauvoir, se sentía prisionera, presa de su mismo cuerpo, ya que éste no le permitía realizar del todo actividades, de disfrutar las diferentes formas en las que podía vivir y más aún era la sociedad la que se empeñaba en tenerla controlada, de enseñarle que lo mejor que podía hacer como mujer era obedecer y callar, además imponerle la idea de que no tenía derecho de exigir lo que le correspondía y lo que deseaba.

El hombre, de acuerdo con de Beauvoir, es el único capaz de idealizar y realizar una vida plena, él se encarga de construirla de la forma que le parezca más benéfica, lo que implica tener derechos políticos y sociales que lo llevaban a conocer, opinar y llevar su vida de manera libre. Estas ideas posicionaron a la mujer, durante mucho tiempo, a estar sumergida en trabajos domésticos, haciendo que las mujeres piensen que su capacidad intelectual para actuar por sí misma es insuficiente. Así con la relación tan estrecha entre los dos, la mujer era considerada incompleta, necesitaba del hombre para poder tener una trascendencia plena, cosa que el sexo masculino podía perpetuar en toda su existencia. Pero ¿Cómo era posible una trascendencia sin tomar decisiones propias, sin tener libertad de elección?

La trascendencia es la que cada uno de nosotros vamos obteniendo por nuestras mismas vivencias y elecciones, al ser oprimidas por esta forma de pensar, a la única trascendencia que podían era la que la otra persona deseaba, sintiéndose su dueño. Lo cual no debía ser así de acuerdo con el pensamiento de Beauvoir, ya que concebía que no se debiera quitar la libertad de otra persona para sentirse pleno, era como quitar la libertad individual, misma que nos pertenece a cada uno desde el momento en que nacemos. La libertad para la mujer la imponía la sociedad al establecer que el hombre era quien debía regir su conducta y libertad, aspecto que generó que fueran vistas como un ente que no estaba condicionado para participar activamente en cuestiones del estado, se le tenía acceso restringido a ciertos lugares y 
no se le permitía una educación como tal, esta era la forma más sencilla de mantenerla pasiva y no reclamara los derechos que le pertenecían, que no comenzara a cuestionarse o indagar sobre lo que se le tenía impuesto en la vida, resultaba mejor que las mujeres ignoraran su verdadera razón de existencia. Pero desde antes existieron mujeres que deseaban tener la libertad de conocer e instruirse en educación. La prueba palpable son las mujeres que como Simone de Beauvoir lucharon por los derechos de las mujeres en vista del amplio recorrido de las olas feministas por De la Heras. La mujer que tenía la fortuna de caminar por el conocimiento mediante la lectura u otras actividades era aprehendida e incluso castigada para imponerle que el conocimiento no tenía que llegar a manos de las mujeres, porque solo harían mal uso de ello, y llegarían a preguntarse por cosas que ya estaban dadas en la historia de la femineidad según el hombre, lo cual resultaba malo para el desarrollo de la sociedad que ellos estaban creando.

Así se iniciaba el sistema patriarcal, "reclamándoles y exigiéndoles a las mujeres que se pensaran ellas mismas como el sexo débil incapaz de poder tener un progreso tanto individual como colectivo". ${ }^{9}$ En el aspecto mitológico de Beauvoir hace un breve recorrido literario para conocer cómo se tenía establecido el ser femenino, en algunos mitos se menciona de manera más explícita una visión mala, de un ser demoniaco que busca desequilibrar la vida, en otros la trascendencia es un estado que se plantea en todo momento en la unión de la mujer con el hombre, pero se vuelve más difícil encontrar la trascendencia de la mujer, por las distintas experiencias que se pueden tener en el placer erótico, los malestares de la menstruación y los dolores del parto, pues para alguna estas son formas de trascender, lo que no está puesto en duda es que si existe una relación profunda de la naturaleza con la mujer, por eso hay situaciones de la naturaleza que se asemejan con la mujer, un claro y vivo ejemplo son muchos escritos como la poesía, en donde la mujer se vuelve parte de la naturalidad de la vida para llegar a explicarlas de una forma maravillosa.

${ }^{9}$ Ídem, p. 30. 
En el aspecto biológico y sexual la mujer también llegó a ser considerada como un ser incompleto que no debía ni podía pensarse que ella era quien debía deliberar que por ella y de ella venia la vida, pues en palabras de la misma de Beauvoir menciona "se admite que la mujer solo lleva y enriquece el semen viviente, pero el núcleo del ovulo es un principio vital exactamente simétrico al del espermatozoide" "10 las dos partes reproductoras de ambos sexos son igual de importantes para poder realizar una fecundación, no podemos suponer que alguno es más importante. Y aún más, es importante que la mujer sea cuidada y protegida, de alguna manera, en su parte sexual, la mujer vive más dramáticamente este proceso de su vida, imaginen lo que es la menstruación, la gestación, la menopausia y la misma vida para el resto del sexo femenino, un hombre creo que no puede opinar en esta parte, él no puede ni siquiera acercarse a lo que es cada una de estas experiencias. Entonces en la actualidad es justó que la mitad, si no es que más bien casi el noventa por ciento sean hombres los que decidan si se debe o se puede autorizar la despenalización del aborto, es un tema bastante importante hoy en día, no es que diga que solos las mujeres saben cómo proceder, pero si son ellas quienes pueden atestiguar si ha sido malo o no que esto se practique.

Una de las principales ideas que se encuentran en la obra, es que la mujer es una construcción social, pues desde que nace se está formando con lo que la comunidad le exige, entonces, desde que se es niña, comienza a darse cuenta de las limitaciones de su propia existencia, empieza a cargar con limitaciones que le son impuestas por la madre o por toda la familia. Si bien tiene que aprender a comportarse, a protegerse y cuidar la ropa, aspecto que hasta hoy en día sitúa a las niñas a permanecer quietas, a no poder realizar ciertos juegos que la lleven a ensuciar o romper alguna prenda, en cambio en el niño se vive diferente la formación, Simone de Beauvoir hace la gran distinción con la que se educan a ambos sexos y como estas diferencias repercuten en la sociedad, pues desde pequeño se le enseña que es capaz de

${ }^{10}$ Ídem, p. 25. 
hacer todo lo que quiera, de manchar, romper, hasta de golpear a otros y todo esto está bien, porque es hombre y debe comportarse como tal, si hay un niño que prefiere quedarse con las niñas a jugar o simplemente al lado de mama se le llama "niñita" y es motivo de consecuentes burlas. Es en la infancia en donde se hace una gran distinción de lo que conllevar a ser hombre o mujer, vas observando quien tendrá más libertad, quien será felicitado por comportarse como su sexo le permite "como todo un hombre".

El sistema patriarcal ha sido tradicionalmente el encargado de explicar cómo se debe de fundamentar la existencia y el comportamiento de la mujer, esto por supuesto, es una dominación construida desde la antigüedad, pues si nos remitimos al texto sagrado de la tradición judeo-cristiana, la biblia, nos encontramos con un pasaje que dice, "La mujer fue creada de la costilla del hombre; no de su cabeza para superarlo, ni de sus pies para pisotearlo. Fue hecha de su costado para ser igual, debajo de su brazo para ser protegida, y muy cerca de su corazón para ser amada" "II, esta frase pregona la idea de la igualdad entre ambos sexos, no se puede seguir con la idea de que la mujer es inferior al hombre, esta frase lleva a pensar que no se podrá en ningún momento querer una superación personal, se necesita ser sumisa, aceptar el amor, la protección y el mandato que el hombre desee y crea que su mujer deba recibir. Necesita ser su acompañante dispuesta a estar con él a pesar de que no le resulte del todo agradable, pues deja su existencia para ser la existencia que el macho quiere poseer, convirtiendo su propio acompañamiento en una especie de servidumbre en la que la mujer está para todo lo que él necesite, sin exigir ni hablar sobre lo que ella en realidad quiere o desea, solo debe remitirse a situarse como esa especie de objeto del que nos habla Simone de Beauvoir, el objeto que está sólo y cuando el hombre lo decida, que se utiliza y se desecha si es necesario, sobajando de esta manera era posible transformar su pensamiento, integrándole la idea de que no podía completar su existencia y

${ }^{11}$ La Biblia de las americas, Genesis 2. 
trascendencia sola, quitándole personalidad, libertad de elección, formas de expresar se volvía más fácil tratar de manipular las diferentes formas de vida en las mujeres.

Es la mujer por quien se cometió el pecado original, acción que produjo la negatividad frente a lo femenino, percibiéndolo como algo malo, ser femenino incapaz de poder tomar decisiones, de poder estar al frente de una sociedad, porque carece de cierta racionalidad que no le permitirá actuar como un ser dotado de inteligencia, a partir de esta anécdota la mujer de cierta forma toma la concepción de que fue creada para no hacer nada de importancia en su vida de forma independiente y para la de los demás, debía sólo atender las necesidades que se le fueran asignando, actuando conforme le fuera permitido, porque si en ella estaba la toma de decisiones solo podría atraer cosas desaprobatorias a la vida, como fue este gran pecado original. Femenino es sinónimo de incapacidad de poder tomar decisiones, de poder estar al frente de una sociedad, porque carece de racionalidad, lo que no le permitirá actuar con inteligencia. La idea central de este mito hizo posible que se desarrollaran distintas ideas de como concebir a la mujer de forma negativa y se arraigó, la imagen de la mujer, como algo malo, de allí que San Agustín dijera que "la mujer es una bestia que no es ni firme ni estable" ${ }^{12}$. En las sociedades de esa época, se le asemejaba con la animalidad, como un ser que no podía ni siquiera de forma irracional luchar por sus ideales individuales, pues hasta resultaba problemático que realizara lo aceptado e impuesto. Se concebía como una bestia incapaz de establecerse en un lugar situado. Para San Agustín ¿Cómo se le podía dar libertad a una bestia que no era capaz de razonar su actitud, su pensamiento y su misma libertad? Esta clase de preguntas eran las que le interesaban a la filósofa de Beauvoir, pues la libertad era uno de los principales derechos que la mujer debía obtener, solo a partir de ellos se podía concebir una existencia que le permitiese ser considerada como un ser humano racional capaz de tomar sus propias decisiones. Para la autora de la obra El segundo sexo, es la libertad lo que justifica las acciones, la mujer debe ser quien construya su vida de la forma que le complazca; sin

${ }^{12}$ De Beauvoir, Simone. (1989). El segundo sexo. Los hechos y los mitos. trad. pablo palant, p. 15. 
embargo, era y se vuelve difícil hacerlo porque las objetivasen de tal forma que dejaban a un lado lo que ellas en realidad sienten frente a las distintas situaciones que cada una vive. ¿Cómo iba a ser posible conocer la naturaleza racional de la mujer sino tenía derecho alguno, ni siquiera sobre ella misma?

A través de la obra se conoce la situación de la mujer en distintos grupos de relación que conlleva, como se fueron concretando ideales de lucha para tener voz en la sociedad y a pesar de que la vida social vaya cambiando, lo único que lograron las mujeres fue mejorar la condición jurídica, en donde ambos sexos tienen una igualdad en todos los derechos frente al estado, esto por supuesto no es muy claro hasta nuestros días ya que en algunos lugares no se acepta que la mujer sea quien participe en la toma de decisiones frente a la sociedad por la creencia de que la mujer sólo existía para atender problemas del hogar. En la actualidad lo que resulta más grave es que existan mujeres con un pensamiento similar y sean ellas mismas las que están oprimiendo a más mujeres, reclamando, exigiendo que deben "meterse en la cocina a atender al hombre", porque son las actividades que les pertenecen, si son mujeres que deciden instruirse y participar en la sociedad, son mujeres libres. Es grave porque nosotros como mujeres actuamos con sexismo y misoginia subordinando la capacidad de todas las mujeres, incluso la misma forma de actuar de uno mismo, así contribuimos a que siga en pie las estructuras de una sociedad machista y patriarcal como lo ha pensado Marcela Lagarde. La realidad es que aunque se tuvieron y se tienen estos pensamientos retrogradas, se debe de luchar para que la mujer pueda obtener más que ser participe en cuestiones del estado, necesita lograr la trascendencia para llegar a ser una persona completa en todos los aspectos personales, que de Beauvoir nos dice que para obtenerla se necesita ser valiente en donde tiene que decidir y afrontar todas las responsabilidades que se desarrollen en su vida, de creer que puede conquistar lo que se corresponde, para dejar de ser el subser al que ha permanecido la mujer por la sociedad y su misma indiferencia a todo lo que le ocurre 
a su alrededor, pues muchas veces prefiere tomar una actitud pasiva y esperar a que su vida se desarrolle como todas las mujeres están acostumbradas.

De Beauvoir se preguntó qué es ser mujer, qué significa serlo y qué es todo lo que conllevaba el sexo femenino a lo largo de la historia. Fue por ello que la obra se convirtió en un manifiesto para reivindicarla emancipación de la mujer en los diferentes espacios en los que se desarrolla individual y colectivamente, considerando las distintas etapas y fases que puede llegar a vivir, comprender que es ser mujer, es difícil porque se necesita entender las distintas formas de vidas que llevan cada una, la adolescente, la madre, ama de casa y obrera, pues cada una se va concibiendo de forma distinta, aquí deberíamos detenernos a preguntarnos si son felices, si en lo que se han transformado las hace ser plenas y felices, no podemos suponer que lo son, porque aunque la mujer tenga sus hijos, su empleo, necesita tiempo para ella, para pensar y reflexionar sobre lo que ha estado haciendo a lo corto o largo de su vida.

En uno de los apartados reflexiona en concreto del papel de la mujer dentro del matrimonio, en donde es vista de una manera más baja, de Beauvoir nos dice "a la mujer se le ve como una propiedad que se adquiere por contrato; un bien mueble, la mujer no es más que un anexo al hombre"13 que requiere al hombre para poder ser completa como ya se ha mencionado anteriormente, no era importante preguntar si quería casarse, porque desde que se es niña se va inculcando que la finalidad en su destino es casarse joven y tener cuantos hijos pudiera soportar, estas ideas son más aceptadas por las mujeres que pertenecían a un estatus económico muy bajo, pues estando en dicha situación se esperaba que "pudieran ser engañas y seducidas por la facilidad de su condición para que aceptaran el papel de madre y ama de casa al que se les buscaba reducir" 14 y así de manera sencilla se lograba lo que decía Balzac "la mujer casada es una esclava a quien hay que saber sentar en su trono" ${ }^{15}$, además de reducir a la mujer al hecho de que no tenía otra opción de elección que el matrimonio, se le

${ }^{13}$ Ídem, p. 141.

${ }^{14}$ Ídem, p. 151.

${ }^{15}$ Ídem, p. 149. 
sobaja al objeto que se compra con dinero para tenerla feliz, cosa errónea porque la mujer no solo tiene necesidades económicas, también busca una felicidad plena tanto en lo psicológico, lo mental y lo fisiológico. "Al hombre le encanta el dominio que ejerce sobre ella; a las imágenes naturalistas del arado que abre el surco que superpone símbolos más espirituales cuando la mujer es una persona; el marido forma a su esposa, no solo eróticamente, sino también moral e intelectualmente; la educa, la marca, le imprime un sello"16. Apenas sentados uno al lado del otro el hombre pone la mano en el muslo de la joven, como un león apreso con su pata el trozo de carne que ha conquistado. A la mujer no la podemos reducir a un simple objeto, ni podemos pensar que solo es capaz de hacer una cosa a la vez, la mujer es idónea para hacer muchas cosas, y hacerlas de manera ordenadas para lograr siempre tener todo en control, se encarga de "los cuidados de la huerta, del corral, de las ovejas y los cerdos son de su exclusiva incumbencia; interviene también en trabajos pesados, cuida la distribución del estiércol, cosecha, arranca las malas hierbas. Además, prepara las comidas y cuida el hogar, lava, remienda ropa, soporta las pesadas cargas de la maternidad y el cuidado de los niños" ${ }^{17}$. Para aclara su idea de mujer trabajadora hace una reseña de la participación activa de mujeres durante cambios importantes en la sociedad, menciona que es justo en el desarrollo de la revolución industrial donde se hace más notoria la participación de la mujer en el trabajo productor, acción que, por supuesto se vuelve peligrosa, pues los hombres sabían que al realizar acciones más difíciles necesitaban un salario, y por consecuente sería posible que la comunidad femenina comenzara a pelear lo que por derecho le correspondía. Efectivamente con dicha acción las mujeres conocieron la mayor independencia por el trabajo, cosa que las llevo a tener libertades de costumbres, de pensarse de manera individual, en donde comenzaban poco a poco la lucha de libertad de elección en ámbitos de relación social. Aunque el sistema patriarcal se encargó de que en el trabajo se sindicalizara a menos de la mitad de trabajadores, así era como la mujer solía ser la menos elegida

${ }^{16}$ Ídem, p. 122.

17 Ídem, p. 177. 
para pasar a serlo, además de que se tenía bajo nivel de salarios para ellas, pues ganaban la mitad del salario de un hombre en una jornada. A pesar de que llegó el día en que abren las puertas fábricas, oficinas y facultades a las mujeres se sigue considerando el matrimonio para ellas como una de las carreras más honorables que la dispensan de toda participación ciudadana.

\section{La experiencia vivida}

La segunda parte, o el tomo II, de la obra El segundo sexo, como bien dice su título, nos lleva a pensar y reflexionar sobre las experiencias vividas que han enfrentado las mujeres, en la adolescencia, la mujer casada, la madre, su madurez y vejez y como estas ayudaron a que Simone de Beauvoir pensara y las uniera para lograr encontrar el camino que se debe seguir la mujer independiente.

"No se nace mujer: llega una a serlo"18, esta frase encierra toda la filosofía feminista de la francesa de Beauvoir, porque el ser mujer es algo que la misma sociedad ha ido imponiendo a lo largo de los años, ni lo biológico, ni lo físico, ni lo económico pueden reducirnos a decir si se es hombre o se es mujer. Cuando en algunas familia nace un varón, desde los primeros años que comienza a tener conciencia se da cuenta de ciertos comportamientos que la familia, día tras día, le exigen para hacerse hombrecito; esto da paso a que se vea de forma vanidosa, e incluso homosexual, si alguno de su mismo sexo pide que lo besen o se ve en el espejo como lo hace una mujer, con toda la actitud que lo rodea lo orillan muchas veces a que se sienta orgulloso de su sexo y comience a generar acciones que todos quieran aplaudir, el ser rudo, fuerte, son comportamientos tan bien aceptados en la masculinidad. Las situaciones de cada uno, de forma individual se desarrollan por el contexto y la sociedad donde nos encontremos. Las vivencias de cada uno dependen mucho de lo que las familias quieren.

18 Ídem, p. 15. 
En cambio a la mujer la educan desde la niñez de una forma distinta, le van hablando de los tesoros de la prudencia femenina, le piden que tenga virtudes, y le enseñan cocina, costura y el cuidado de la casa, la peinan de manera complicada y le van proponiendo e imponiendo reglas de compostura que debe seguir durante toda su vida, "la comprometen a convertirse en una sirvienta y un ídolo" ${ }^{19}$ que muchas de las veces, o la gran mayoría, no piensan o las dejan pensar sobre lo que realmente quieren para su vida. Aquí encontramos un gran problema que sigue en la actualidad la forma en que les hablan en casa va propiciando la manera en que vivirán su futuro, se vuelve necesario que desde la infancia hagan entender que diversas actividades como son las del hogar pueden ser realizadas por el hombre, y que de manera equitativa existían labores que la mujer puede manejar.

En la historia solo se ha hablado de grandes hombres, y en caso de que aparezca una mujer, siempre está acompañada de un varón o a realizado una mala acción, "los hombres son los emisarios de Dios sobre la tierra, como el papa y los obispos, cuyo anillo se besa, el sacerdote es el que dice la misa, el que predica y aquel delante de quien hay que arrodillarse en el secreto del confesionario" ${ }^{20}$. Porque se ha dejado de lado a la mujer en las actividades de la iglesia, si hay representantes, si hay mujeres, pero han sido los hombres los que han tenido el mayor poder.

La civilización patriarcal también ha destinado a la mujer a la castidad, está confinada al matrimonio, ella debe regularse en primera instancia por lo que su familia le dice, después es lo que su marido le permitirá. "En el matrimonio sucede que la mujer no quiere tener hijos, por salud, o porque representa una carga para el joven matrimonio y esto provoca que el erotismo de la pareja se paralice por la prudencia" 21 lo mejor que debe ocurrir dentro del matrimonio es que la mujer tenga libertad de elección de si quiere procrear y en qué momento de su vida lo quiere. En este aspecto se vuelve necesario hablar sobre los métodos anticonceptivos, que mucho antes solían

\footnotetext{
${ }^{19}$ Ídem, p. 27.

${ }^{20}$ Ídem, p. 35.

${ }^{21}$ Ídem, p. 134.
} 
verse como una trasgresión a la naturaleza, cuantas veces no hemos escuchado de las mismas mujeres que debes de tener los hijos que Dios te dé, claro que no debe pensarse así, creo yo que la responsabilidad de tener hijos, educarlos y criarlos es solo nuestra, y así con la práctica de los métodos anticonceptivos se vuelve más segura y libre la parte de la sexualidad de la mujer, y sobre todo se lleva a tener madres y padres más seguros al momento de ser padres.

Abonando a este punto sobre la sexualidad de la mujer es necesario que sepamos, que su finalidad es incierta, es de naturaleza más psíquica que fisiológica, no se busca satisfacer solamente, requiere de encontrarse a sí misma en todos los aspectos. En la mujer casada uno de los apartados de este tomo, centra esta idea de una sexualidad mal entendida, pues como ya se ha mencionado anteriormente, el matrimonio en algunas sociedades es la finalidad de la mujer en la sociedad. Pensemos porque en la actualidad se ha llegado a tantos divorcios, pues la mujer y el hombre han entendido de alguna manera que no siempre se debe de quedar uno con una pareja por la ley o por los hijos. Se trata ya de un nuevo habitus que nos permite estar más abierto a las relaciones que se dan. Si busca más que un proveedor económico decidirá dejar a su pareja para encontrar las satisfacciones individuales, en donde con su pareja podrá tener y gozar de una independencia que le permita ser trascendente.

En el matrimonio los dos se necesitan, socialmente es el hombre el que recibe todas las virtudes pues se identifica como un individuo autónomo y completo encargado de producir y es así como se logra justificar su existencia "la vocación del macho es la acción: necesita producir, combatir, crear, progresar, trascender hacia la totalidad del universo y la finitud del porvenir, y a la mujer el matrimonio tradicional la confina a la inmanencia" 22 la mujer debe aceptar cómo debe justificarse frente a la sociedad, debe dar hijos, no es malo, pero se pudiera ver que no es la única razón por la que tiene existencia, se debe considerar que sea madre siempre y cuando, se sienta preparada. Su función dentro del matrimonio es satisfacer a su marido, ¿dónde queda

${ }^{22}$ Ídem,p. 204. 
lo que es ella?, lo que siente, lo que quiere y lo que piensa, no se debe ver como un simple servicio que está las veinticuatro horas del día para él. Se ha dejado y aun se sigue dejando a un lado lo que constituye a la mujer madre, ama de casa y cuidadora de sus hijos, pues de alguna manera comienza a relacionarse tan profundamente con sus labores del hogar que le permiten una huida lejos de lo que es en sí misma, inicia de una forma a considerarse parte de su hogar como si fuese la única capaz de poder realizarlo y es donde se logra identificar que muchas veces puede llegar a sentirse completa con eso o incompleta porque solo existe para organizar su alrededor, la soledad pesa más sobre la mujer en la medida de las tareas que realiza y se vuelve todo rutina para ella. Como un ser individual también necesita de espacios que la lleven a reflexionar su entorno, de identificar a donde quiere dirigirse y que necesite hacer para llegar a cumplir una de sus metas. La meta no se puede decir que es solamente el matrimonio, hay muchas más que cada mujer va definiendo por sus vivencias y capacidades intelectuales.

Lo ha mencionado de Beauvoir en su obra, se piensa que el narcisismo es una actitud característica de las mujeres, lo cual no puede ser, ya que el yo se siente definido y acabado, en la mujer el yo es algo que se va constituyendo con el paso de los años y más aún necesita consagrar su amor. Para la mujer el amor anhelado reencarna en el individuo como una situación, el amor para ella lo es todo, es entregarse en cuerpo y alma, y a la vez espera ser querida como fue desde pequeña, bajo el control de los mayores. Las frases "pequeña mía", "mi niña querida”, las utilizan muy a menudo los hombres porque son las palabras que llegan con seguridad al corazón de la mujer, y es así como la mujer va considerando el amor que las personas le van ofreciendo, y es así que la mujer reencarna y revive la situación de la protección de los mayores. De forma mística se le muestra a las mujeres que el amor es una de las vocaciones que tienen que seguir, pues es esa la situación en donde ellas la mayoría de tiempo deberían sentirse plenas, pero quizás no es así, muchas veces el amor se refleja hacia la mujer como una situación de sufrimiento cuando este no es 
regresando de la misma manera, la mujer siempre está esperando mucho y es ahí donde viene la decepción de encontrar un verdadero amor, la filósofa de Beauvoir menciona el su texto, "el día en que la mujer pueda amar con sus fuerza y no con su debilidad, no para huir de sí misma, sino para encontrarse, y no para renunciar, sino para afirmarse, entonces el amor será tanto para ella como para el hombre una fuente de vida y no mortal peligro" ${ }^{23}$, es importante señalar que los dos necesitan saber cuál será la finalidad última de una relación, aceptar las diferencias y libertades que los dos quieren lograr.

La libertad es un aspecto que ha costado mucho trabajo obtener por parte del sexo femenino, aunque se haya tenido mucho avance en cuestiones cívicas como los derechos, la mujer no puede ser del todo libre sin una economía individual que le permita autorregularse y complacer las necesidades que tiene. El trabajo ha sido el medio por el cual la mujer poco a poco a podio ir superando las diferencias que existían frente al sexo femenino, esto ha subsanado la idea de ser parte de la sociedad en la que los dos son importantes.

Entonces ya existen dos vías que la mujer puede decidir, entre la resignación a lo tradicionalmente establecido, o la lucha constante para llegar a ser una mujer independiente, esta lucha se ve duplicada por diversos factores, porque se entra en la situación de encontrar el camino correcto que guie para cumplir metas, atender de forma individual los problemas que puedan surgir. Quiero terminar este apartado que hace referencia al segundo tomo de la obra se Simone de Beauvoir con una cita que me parece que sigue vigente, pues engloba lo que en la actualidad sigue viviendo la mujer, siente las mismas preocupaciones porque la cultura es tan rígida que es difícil que se desprenda de ideas, Beauvoir nos dice "la mujer independiente se halla hoy en día dividida entre sus intereses personales y las preocupaciones de su vocación sexual”" siguen las preocupaciones de atender las exigencias de una sociedad, en donde debe demostrar su capacidad, porque si no lo hace los comentarios serán los mismo que los

\footnotetext{
${ }_{23}$ Ídem, p. 456.

${ }^{24}$ Ídem, p. 485.
} 
del pasado, y por otro lado la moralidad y el miedo a no actuar de buena manera y de la misma forma sea señalada por la sociedad, son aspectos que hoy en día pesan mucho en las mujeres.

\section{Hacia la mujer independiente: El feminismo de Beauvoir en López Pardina}

La filosofa Teresa López Pardina ha estado a cargo de investigaciones feministas desde la filosofía de Simone de Beauvoir, al igual que su tesis doctoral a tratados los temas relevantes de esta misma, siendo revisada por otra feminista importante como cela Amorós, es por ello que he decidió apoyarme desde su artículo para la redacción de este trabajo.

López Pardina menciona que Simone de Beauvoir perteneció a la filosofía existencialista y, por tanto, no podía concebir al ser humano sin libertad y dador de sentido a su existencia. Además, si nos centramos en su concepción feminista, esta misma visión se ve reflejada en lo que debía de obtener la mujer en sociedad: libertades que le permitirán autoconstruirse de la forma que a cada una le pareciera más conveniente, pues a partir de ello se logra la trascendencia y la independencia logro que en la vida se debe colocar como lo primordial. Al respecto López comenta "Los conceptos fundamentales de su filosofía le sirvieron como herramientas fecundas para explicar la opresión de las mujeres y las vías de su emancipación” 25 .

López dice que centrándose en la libertad, una libertad que fuera más allá de las mismas costumbres que ya estaban impuestas, Simone de Beauvoir de alguna manera hace reflexionar, al leer la primera página del libro El segundo sexo las acciones que de forma automática han repercutido en actividades que hacen o reflejan lo que es una mujer, cada una va cargando con una cierta carga teórica y costumbres que han imperado desde sus bisabuelas, o desde más antes, porque la forma de pensar y vivir se van adaptando de alguna manera sin que sea planeado, cuando se

\footnotetext{
${ }^{25}$ Lopez, Pardina, Teresa. Beauvoir, la filosofía existencialista y el feminismo, Instituto de Investigaciones Feministas. UCM, p. 99.
} 
reflexionase van dando cuenta que se actúa de una manera que no es totalmente libre, porque siempre se piensa primero en lo que antes no se ha realizado.

La autora Teresa López Pardina nos lleva a preguntarnos por qué el feminismo filosófico surgió con más fuerza que las otras disciplinas que también eran desarrolladas por una parte de la sociedad femenina como, el arte, la literatura, quizás porque no podían avanzar ninguna de éstas sin primero establecer cuál era el papel que le tocaba desarrollar a la mujer en los distintos campos de trabajo y relaciones sociales, sin esto era imposible que se diera paso a el desarrollo de este pensamiento en otras disciplinas. Simone de Beauvoir inicia con toda una carga de conceptualización del existencialismo, lo que propició que de una manera diferente y nueva se diera el esclarecimiento de lo que son las mujeres, "esos seres disimétricos e inferiores al otro componente de los grupos humanos que son los varones" ${ }^{26}$, si bien la autora tiene la idea clara de que a la mujer en ningún momento o aspecto se le considera como igual del hombre, simplemente es el "otro", el objeto que de Beauvoir se encargó de explicar en su obra. La obra El segundo sexo para López Pardina es considerado como un corpus que va desarrollando la desigualdad entre mujeres y hombres creada desde una construcción cultural, y que a partir de ello se debe comenzar para remplazar una construcción igualitaria y justa que termine con la opresión, y al final se logre un estado de distensión que lleve a mujeres y hombres a una convivencia fraternal y libre.

La relación más sencilla de reflejar esta convivencia sin tensión entre ambos sexos es la comparación que hace Pardina entre El segundo sexo y El contrato social, en donde el segundo se encarga de establecer las bases de la democracia moderna y la obra de Beauvoir lo hace de una forma total y efectiva, en donde todos son considerados de la misma manera. Rousseau al comienzo del escrito El contrato social inicia con una frase en donde detalla que el hombre es el único que necesita liberarse, aspecto que tanto la autora como criticas femeninas han demostrado que solo se pensaba en los varones como personas importantes en la vida, a todo esto se le

${ }^{26}$ Ídem, p. 100. 
relaciona la frase tan famosa de nuestra feminista Simone de Beauvoir, "No se nace mujer..., es decir no nace sensible, callada, sumisa, impresionable, dócil, indecisa, en definitiva, oprimida"27, se hace llena de estas características desde el momento en que la historia la decidían los hombres, las dejaban en un segundo término del cual no necesitaban, no actuaba para demostrar la capacidad de la femineidad. El gran pensamiento que se expresa en El segundo sexo da lugar a una teoría critica que se apega a la tradición que inicio en el siglo de las luces y que más tarde se continuo por las sufragistas, se unió a las luchas que cada ola feminista venia defendiendo, fue gracias a ello que se pudo dar lugar al feminismo como una teoría critica estructurada.

Al remitirnos al segundo volumen de la obra, nos encontramos con una frase inicial que dice, "no se nace mujer; la mujer se construye", a lo que López Pardina interpreta como el núcleo que encierra el eterno femenino como un mito masculino, en donde la construcción socio-cultural impera en las diferencias de sexo y género. De Beauvoir realiza una comparación igualitaria por la naturaleza en los aspectos biológicos, para lograr exponer la importancia de ambos sexos para la vida y la existencia, no se podía irracionalizar las distintas vivencias que se tienen desde lo mero femenino, ni de lo exclusivo masculino, "la femineidad es algo artificial, no natural; los factores biológicos no determinan la forma de ser"28 no podemos reducir nuestro pensamiento al identificar que si se es mujer, es necesariamente débil, o que si se es hombre debe de ser violento por mencionar acciones que se creen a veces como orgullo del sexo masculino.

El origen de esta importante obra surge desde la primera intención que de Beauvoir tuvo por escribir sobre sí misma, pues ella se da cuenta de lo que significa y las problemáticas que se desarrollaban al ser mujer en la sociedad de su época, pues en sus primeros escritos autobiográficos hace críticas a las mujeres por sus comportamientos, y vivencias que las llevaban a una enajenación frente a los problemas, porque poco a poco sentían que así era como debería de ser su realidad, no

\footnotetext{
${ }_{27}^{2}$ Ídem, p. 101.

${ }^{28}$ Ibídem.
} 
hubo en su tiempo una revelación o revolución de lo que la sociedad les exigía al paso de los años como mujeres. Su filosofía feminista y existencialista dieron paso a una filosofía de la libertad en donde analizaba que en los humanos la libertad era escasa, pues para ser más concretos la existencia del ser humano necesita libertad, y esto resultó apropiado para mostrar la falacia del eterno femenino y su construcción sociocultural, pues de esta forma se iban construyendo a las mujeres, sin alguna libertad de elección y expresión, pero era y es todo lo contrario lo que necesita la mujer, pues debe tener libertad en todos los aspectos y autonomía que le permitan comportarse y gozar de la vida.

La primera cuestión a la que se enfrenta De Beauvoir, es explicar para ella qué significa el hecho de ser mujer, lo que resultó quizás muy difícil de identificar, pues para ella ser mujer nunca la posicionó en un grado del cual no podía actuar, nunca fue un obstáculo para ella, puesto que realizaba lo que se proponía en cada momento, lo que si dejaba claro es que se dificultaba siempre serlo porque los mitos de la cultura habían sido construidos por los hombres y las mujeres necesariamente eran como los varones lo deseaban. La sociedad femenina que la rodeaba si tenía problemas, porque se regían a lo que la comunidad les pedía, tenían que cumplir y hacer lo que era bien visto en sociedad. El hecho de ser mujer si llevaba a pensarse diferente, desigual con relación a los hombres, pues casi siempre la opresión del sexo opuesto imperaba en las formas vivenciales de cada sociedad. "Las mujeres sufrimos la degradación ontológica y moral de la opresión en múltiples escalas y desde múltiples instancias"29 porque desde las costumbres impuestas y la educación que se les brinda ya sea en casa o en alguna institución llevan a la descripción de tomar una forma pasiva y obedecer las decisiones tomadas por otros. La publicidad de cualquier cadena televisiva atribuye roles a las mujeres como limpiadora, pulidora del hogar, cocinera y cuidadora de la familia, en ningún momento observamos que en algunas campañas publicitarias se muestra al hombre como ese ser humano que también intervenga en estos roles, con

${ }^{29}$ Ídem, p. 104. 
objetivo de ayuda y compartimiento de tareas. El ser humano no es solo naturaleza, es un ser libre que debe y puede afrontar adversidades, centrándonos en la vida de las mujeres era más fácil controlar de alguna manera su cuerpo, con el avance de los métodos anticonceptivos se le entregaba más libertad de elección al decidir si tener hijos y cuantos, el feminismo impulso a las leyes de la despenalización del aborto y el uso más libre de anticonceptivos, la libertad de opción sexual.

En más de dos capítulos Simone de Beauvoir expresa las molestias de la menstruación, afirma que el embarazo es un trabajo para el cuerpo, que gasta energía y no representa algún beneficio individual para las mujeres desde un punto de vista fisiológico y desde el punto de vista perceptivo es una alienación. Aspecto que resultó escandaloso por la forma de pensar conservadora de la época.

El segundo sexo es un libro con carga política en medida de la filosofía, porque lleva a la acción de ejercer la libertad y la autonomía de todo individuo. Al final del segundo tomo nos habla de la liberación, y para llegar a ello se necesita primero la independencia económica, y la afectiva, que se puede lograr con la educación igualitaria para alcanzar los mismos niveles y que las diferencias sean individuales y no por el sexo. La liberación es una lucha que comienza individual, pero debe seguir de forma colectiva, pues es necesario que la sociedad cambie para llegar a lograrlo plenamente.

\section{Edith Stein la madre sabia y Simone de Beauvoir la mujer libre: según Tapia Gonzáles}

Georgina Aimé Tapia González tiene líneas de investigación centradas al feminismo, estudios de género y ética ecológica. Es importantes resaltar la visión de la filósofa Aimé, por la contribución de generar una especie de dialogo entre Stein y de Beauvoir, a pesar de la diferencia de épocas en las que las dos se desarrollaron, además de las distintas ideas sociales que imprimían cada una de ellas desde su vivencia individual. Pues trata de emparejar y retomar las ideas de la mujer que ha sabido desarrollar su idea de independencia desde el hogar. 
"Ambas autoras coinciden en haber planteado la cuestión de las mujeres como una problemática compleja abordada desde la filosofía en diálogo con otras disciplinas". ${ }^{30}$ Las dos merecen ser reconocidas por sus contribuciones a la teoría feminista que se gestó en su época. Edith Stein hace de la fenomenología una teoría de la filosofía sobre las mujeres, Simone de Beauvoir vislumbró en el existencialismo la filosofía de la libertad para exponer el problema del segundo sexo. Las dos buscaron la forma de hacer una filosofía propia, abierta a la interdisciplinariedad y la reflexión de problemas que no habían sido considerados importantes en la filosofía.

Desde la concepción de Beauvoir la filosofía se encarna en la existencia, que debe partir de la toma de conciencia de sí, desembocando en el ámbito político para la práctica de la libertad. Las dos pensaban que filosofía y feminismo reclamaban coherencia con la propia existencia, el filosofar se daba en todo momento de la vida, y el pensamiento se reflejaba en la teoría y la práctica, lo que las llevo a vivir conforme pensaban y que era poco común dentro de la historia biográfica de los filósofos, "Edith Stein encarna a la madre sabia, mientras Simone de Beauvoir da a luz a la mujer libre" ${ }^{31}$.

Las obras Estrellas amarillas y Memorias de una joven formal son muy importantes para comprender el despertar de la vocación filosófica de ambas y sobre todo de entender su pensamiento inclinado hacia una teoría feminista, "ambas guardan entre sí un paralelismo extraordinario que, página a página, desvela sendas inéditas abiertas tras duras luchas, sendas que hoy son transitables para muchas mujeres" ${ }^{32}$ el andar de las dos feministas ayudó a que hoy en día muchas mujeres tengan acceso a la educación y trabajo, así como libremente decidir sobre su sexualidad, y sobre su cuerpo.

Stein rodeada de una familia numerosa y entregada a la religiosidad judía, y de una madre viuda decide quedarse con el negocio de maderas de su esposo para

\footnotetext{
${ }^{30}$ Tapia, González, Georgina Aimé. Edith Stein y Simone de Beauvoir: Filosofía, feminismo y experiencia vivida. Universidad de colima. México, p. 137.

${ }^{31}$ Ídem, p. 139.

${ }^{32}$ Ibídem.
} 
asegurar el futuro de sus hijos, conoce de esta forma Stein a una madre fuerte, llena de iniciativa, alejada de la mujer dependiente de la economía, conoce a una familia alejada de los estereotipos tradicionales, en donde fueran las mujeres quienes recibieron formación profesional. Desde una parte opuesta de Beauvoir, nacida en una familia burguesa decimonónica, conocía al padre que se ocupa de los asuntos importantes, mientras su madre era encargada de las labores del hogar y cuestiones de educación, religión y moral, pensaba que su madre gozaba de mucho prestigio y buen estatus social, pero con base en ello se formaba como el ser que debe obedecer al hombre, la mujer que Simone no quería llegar a ser.

Aunque ambas obtuvieron una relación y enseñanza diferente de parte de sus madres, fue lo que las empujo a trabajar en la cuestión de la femineidad de una forma distinta, las dos mostraron gran inteligencia, perdieron la fe desde la adolescencia, obtuvieron una profesión, lucharon por los derechos de las mujeres y se construyeron libremente ante los limites culturales delineados para la mujer. Edith Stein después de haber sido reconocida como brillante en el trabajo filosófico, es rechazada ante su petición a una cátedra universitaria, pues el mismo Husserl argumenta que el puesto es más apropiado para un hombre porque el hecho de ser mujer la llevaría al matrimonio y tener hijos. A pesar de que fue constante en la lucha para obtener una cátedra y dirigirse al Ministerio Prusiano de Ciencia y Educación le fue rechazada rotundamente su petición primero por ser mujer y segundo por ser judía. Después de su experiencia docente y conferencista en temas de educación para las jóvenes se da cuenta que no basta que la mujer tenga acceso a la formación profesional, porque se siguen enfrentando a discriminaciones en la familia, la sociedad, la política, la religión y el trabajo remunerado. De Beauvoir no corrió con la misma suerte, para ella fue un tanto más fácil acceder a la educación universitaria, pues al final cumplió su sueño de ser una escritora, y sobre todo de ayudar a la emancipación de la mujer con su obra. Stein hace más una lucha en la toma de conciencia en la paridad entre hombres y mujeres en todos los aspectos sociales y de Beauvoir manifiesta su inquietud con 
respecto a la doble moral permisiva para los hombres y represiva para las mujeres. "Desde muy jóvenes decidieron forjarse un destino fuera de las normas de una sociedad estereotipada y sexista donde las mujeres eran consideradas seres humanos de segunda categoría" 33 .

Edith Stein inicia reclamando la universalización de valores tradicionalmente femeninos, la comprensión, la ternura o la sensibilidad, considera que la maternidad espiritual constituye los valores humanos y no debe reducirse solo a lo femenino, lo femenino para ella es esencial en todo lo humano, uno hombre bien puede actuar sensible o tierno frente a algunas situaciones. Llegó a plantearse la cuestión de las diversas interpretaciones sobre los papeles desempeñados por ambos sexos en las escrituras sagradas, así como la relación entre Dios y las mujeres. La esencia femenina de la que ella habló se refiere a la maternidad espiritual, como un proyecto abierto a la creatividad de las mujeres, de independencia al decidir si tener o no hijos e hijas. De acuerdo con su filosofía sobre las mujeres, la igualdad, la autonomía y la solidaridad entre los sexos remiten a una igualdad de todos los seres humanos ante Dios. Examina la imagen construida de la mujer desde el idealismo alemán, el psicoanálisis y la filosofía heideggeriana, descubre la misoginia en la ideología romántica, la indiferencia del marxismo ante las problemáticas de la mujer, así como la exclusión de los rangos eclesiásticos dentro del catolicismo.

En cambio, Simone de Beauvoir dejó un conjunto de ideas para pensarlas en la situación histórica, cultural y étnica, ideas que inspiran a elegir la libertad con todas sus cargas y peligros, pues para llegar a ser lo que una mujer quiere ser, nos dice la filósofa que se debe hacer una construcción con las propias decisiones. Stein y Beauvoir afirman que la esencia de la persona remite en su existencia, pero se separa al acentuar la diferencia de los sexos, en una es cultural y en otra es ontológicos. "Mitificadas, veneradas en el temor, exhibidas como trofeos, intercambiadas como

${ }^{33}$ Ibídem, p. 141. 
mercancías o enlazadas como esposas y madres ejemplares se les ha negado sistemáticamente el reconocimiento a la humanidad"34.

Las dos partiendo desde su misma experiencia individual ayudaron a develar la importancia de la mujer en todos los aspectos sociales, un más centrada al catolicismo y la otra más a la libertad otorgada por la sociedad, ambas lograron interpretar y exponer cuán importante y capaz es la mujer al enfrentarse a la sociedad de una manera libre, en lucha y reflexión en cada momento de su vida.

\section{La perspectiva filosófica de la mujer}

No se puede subestimar la obra de Simone de Beauvoir aun en nuestros días, ya que por medio de ella trata de incitar la reflexión en sus lectoras, tanto colectiva como individualmente, pues les propone una nueva forma de vida que puede llevar cada una, de cómo las decisiones involucran la formación de un futuro, además de que dialoguen consigo mismas como mujeres y como personas, para preguntarse por ejemplo, qué esperan en el futuro cuando decidan una relación matrimonial, ¿piensan en la aceptación de hijos o no, piensan en todo lo que se tiene que realizar para ser una mujer independiente? Es por ello que Femenias indica que: "Vanguardista y radical, venerada y refutada, admirable y quizá detestable, Simone de Beauvoir ha perturbado generaciones de mujeres alrededor del mundo"35. Este pensamiento desarrollado por de Beauvoir en la actualidad está vigente en la sociedad, pues muchas mujeres han asumido la responsabilidad y la realidad de enfrentarse a distintas problemáticas por obtener un empleo, obtener una mejor vida individual.

Lo que buscaba desde un inicio la filósofa era denunciar la lógica de la opresión sexual como la forma más notoria, para establecer cómo pocas veces se consideraba el carácter cultural del eterno femenino. De hecho, en los dos tomos de la obra, de Beauvoir explica qué es el ámbito sexual en donde más la mujer sufre su

\footnotetext{
34 Tapia, Gonzalez, Gorgina Aimé, Edith stein y Simone de Beauvoir: Op. Cit, p. 148.

${ }^{35}$ Femenias, María Luisa. (2008). "Simone de Beauvoir, contribiuciones de una filosofa". En La manzana de la discordia. Julio-diciembre, p. 8.
} 
realidad, desde que se es adolescente $y$, consecuentemente, cuando llega la edad madura. Se debe de penar que como todo lo demás, la parte fisiológica es una de las más importantes que constituyen a la mujer, a partir de ahí ella comienza a sentirse plena.

El segundo sexo dio paso a muchas críticas y también a que se relacionara con distintos temas o problemáticas, como la cuestión de las dos guerras mundiales, pero desde la visión de María Luisa Femenias "la obra busca aclarar, enseñar, moralizar respecto de un problema largamente abandonado por la filosofía francesa tras el relativo éxito del ideal ilustrado" 36 . Debido a esto es que se encuentra en ella un espíritu crítico y una argumentación contundente que llevan a de Beauvoir a comprometerse con lo que buscaba realizar.

En su obra no deja de lado ningún tema que relacionara la vida de la mujer. El problema que se buscaba resolver era ¿Qué es la mujer?, cuestión que comenzó a responder como una construcción social que se va a adquiriendo con el paso de los años, desde la infancia hasta la vejez, según de Beauvoir. Esta pregunta en particular dio lugar a que se hiciera un debate en donde participaron Antoine Léonard Thomas (I732-I785), Denis Diderot (I7I3-I784) y Mme. Louised'Epinay (I726-I783), donde trataron la naturaleza femenina, en un aspecto ético-político, abordaron la ciudadanía e igualdad de derechos. Antoine Léonard Thomas redactó un escrito con el título ensayo sobre el carácter, las costumbres y el espíritu de las mujeres en diferentes siglos, en donde realiza un recorrido de cómo se han desarrollado las mujeres en las relaciones sociales, y a partir de ahí trato de hacer una defensa en donde mostraba las virtudes que tenían las griegas y romanas. Las costumbres y la moral de las mujeres mencionaba Thomas se relacionaban con el cristianismo para volverlas austeras y puras, para seguir las enseñanzas de la iglesia para llegar a la categoría de santas, cosa que desde un punto de vista más libre así solo se buscaba la docilidad de la mujer frente a las relaciones que podía conllevar a lo largo de su vida. Las mujeres

36 Ídem, p. 8. 
tenían valentía desde mucho antes, al llegar a actuar indirectamente en las guerras, en instruir a los barbaros con educación, mostraron la gran habilidad que podían desarrollar. Femenias nos dice que Thomas además de mostrar con ejemplos lo que las mujeres son capaces de hacer desde la antigüedad, se propone a distinguir cuatro tipos de espíritus que están presentes en todos, pero el específicamente buscaba encontrar cuales están en las mujeres, uno es el espíritu filosófico, el de la memoria, la imaginación y el político o moral, como concusión encuentra que el que está más presente en ellas es el de la imaginación por la multitud y variación de sensaciones que su belleza y gracia provocan.

Simone de Beauvoir desde la visión de Femenias es vinculada con su estilo ensayístico en la obra con grandes moralistas franceses como Diderot, pues en un argumento de igualdad menciona que la naturaleza humana no hace distinciones de sexo, lo que hace que todos sean portadores de vicios y virtudes, lo cual lleva a pensar que al igual todos merecen tener derechos. A si es como la autora francesa utilizó el método progresivo-regresivo según Femenias, método que le permitió dar a conocer la historia de las mujeres hasta la situación de su época, y así descubrir los prejuicios y falsos argumentos que se sostenían en la realidad. Este método tiene dos dimensiones, diacrónica y sincrónica, en el primero se establecen los puntos de referencia conceptual que configuran la vida, el segundo es la reconstrucción del modo que viven las mujeres como miembros de la vida social.

De Beauvoir parte desde la experiencia vivida, en la que ella como mujer no podía dejar de señalar aspectos importantes que conforman el ser mujer, pues abarcando los distintos puntos específicos de la vida, señala la reconstrucción que llegaron a tener las mujeres por muchos años desde la ignorancia hacia sí mismas, es por eso que "Beauvoir teoriza sobre la acción y la existencia humana desde su situación de mujer" ${ }^{37}$, y es de reconocer que se propuso a hacerlo, pues si bien ella siempre optó por tener una vida libre, sin prejuicios, no fue una mujer que estuviera

37 Ídem, p. 13. 
encerrada, obligada hacer lo impuesto, sino que ella misma se iba formando con sus decisiones, lo que hizo fue para ayudar a todas las demás que quizás no estaban en su misma situación. Aunque de Beauvoir siempre tuvo claro que la libertad era algo por lo que se tenía que luchar y mantener por toda la vida, menciona Femenias, "no es idealista y sabe que los espacios de la libertad se configuran históricamente; son móviles, se ganan y se pierden y obedecen condiciones históricas mutables" (id), que siempre era necesario tener la actitud de lucha por las diferentes épocas y lugares que se encontraran, pues no era de suponerse que si la lucha de igualdad de géneros frente al estado les permitió el derecho al voto, era de pensar que se terminaba la lucha, se debe continuar para qué poco a poco las mujeres vallan obteniendo las distintas libertades que les habían sido negadas.

El avance de las tecnologías ha ayudado a la mujer en varios aspectos, pues con las formas de comunicación en el mundo se ha podido llevar a muchas partes lo que es el feminismo de Simone de Beauvoir, en cada lugar los medios de comunicación han llevado a leer y analizarlo desde perspectiva propias de la vida de cada mujer, dependiendo del contexto en el que se han desarrollado, consigo las diferentes autoras que han seguido su línea y a través de una crítica o una reflexión de la obra han apoyado a que sea más fácil de llevar la filosofía feminista de Beauvoir a la práctica, comenzando desde la manera de actuar y decidir. "Las mujeres existen, al menos por el momento. Y esto nos obliga a seguir buscando una respuesta" ${ }^{38}$, pues los problemas que antes se gestaron fueron importantes de resolver, pero ahora también es momento de centrarnos en las problemáticas sociales que involucran a la mujer en nuestros tiempos, los feminicidios que hasta nuestros días se han vuelto un problema grave, del cual no se debe de querer escapar. Este problema resulta ser la indiferencia de muchos hombres al no querer comprender el avance que ha tenido la mujer en muchos aspectos, pues no es justificable el daño moral y físico que le pueden llegar a ser a una

\footnotetext{
${ }^{38}$ Morant, Isabel. El segundo sexo de Simone de Beauvoir y el feminismo contemporáneo. Revista de la facultad de geografía e historia. p. 106.
} 
persona por el simple hecho de no querer verla avanzar o no soportar que decida divorciarse.

Las mujeres siempre son más sentimentales, pues todos los relatos y momentos más significativos los traducen desde su infancia y para ellas se vuelve necesario que las cosas funcionen con amor y cariño como cuando estaban niñas. La mujer debe constituir lo que es y lo que será en un futuro, muchas veces reflexiona sobre lo que se está realizando y lo que debería cambiar o hacer, esto puede ser consecuencia por la forma histórica negativa en que se ha vislumbrado a la mujer, pues desde la filosofía clásica hasta textos religiosos que son más aceptados por la mayoría de las personas ven a la mujer como algo negativo, la mujer es un hombre fallido, un ser relativo, su cuerpo es desvalido, en cambio quizás un hombre jamás piense en querer escribir sobre su situación social, "un hombre nunca empieza considerándose como un individuo de un sexo determinado" ${ }^{39}$, esto se puede dar por la forma en no querer muchas veces expresar lo que de verdad les incomoda de su sexo por el hecho de que han sido educados para no estar quejándose de las cosas. Morant no muestra que el problema de la alteridad del cual nos ha hablado Simone de Beauvoir radica en las relaciones que llevan hombres y mujeres, no han llegado a la mayor reciprocidad en la que uno se situé en el lugar del otro para poder entender su realidad.

Decir o comprender qué es ser mujer se vuelve un tanto fácil de decir, es una matriz, es una hembra, palabra peyorativa que confina a la mujer a los límites de su sexo, a ya no querer comprenderla desde otra situación sino más que confinada a lo que la biología tiene preparada para ella, y nada más. Que hubiera resultado si las mujeres al igual que el hombre desde la antigüedad obtuvieran las mismas libertades, quizás hasta nuestros días el pensamiento machista estaría erradicado, se dejaría atrás todas las acciones que hoy en día han perjudicado tanto a las mujeres desde su condición psicológica y física. De Beauvoir desde el inicio pensaba en la idea de fraternidad, entendida como reciprocidad de trato, en todas las relaciones, de 
colaboración diaria en donde se pensará la paz en ambos sexos, cosa que quizá hubiera funcionado bien desde el principio, pues existiría esta mentalidad de ayuda entre hombre y mujer, no de superioridad entre ellos.

Morant nos menciona que la idea que refleja Simone de Beauvoir, es la de la conformidad que las mismas mujeres muestran en su situación, no es necesario que desde antes estuvieran renegando de su vida, no se trata de eso, se supondría que cada una estaría reflexionando su vida desde lo que ya está dado y desde lo que quieren obtener, de esa forma se pondría en práctica la ética de la libertad y responsabilidad a la que nos quiso llevar de Beauvoir con su obra el segundo sexo, una ética, en donde el sujeto, sea hombre o mujer justificaran desde si mismos las acciones que se han realizado y no se protegieran con la existencia de un Dios.

No se podía cometer algún acto malo, y decir que Dios ha sido quien ha obrado por la persona, individualmente tomamos decisiones que no llevan a distinguirnos de los demás, lo que de cierta forma no desunía a las mujeres de una forma personal era la problemática abordada por la francesa de Beauvoir, pues al exponer temas centrales en la vida de las jóvenes puso de manifiesto la ignorancia que muchas veces se lleva por muchos años. Al comenzar a leer la obra, El segundo sexo, se puede interpretar que se cumple uno de los objetivos de la autora, pues desde el comienzo la mujer se va sintiendo identificada y comienza a pensar su historia desde los puntos señalados, lo cual hace o debería de hacer que se produjera en cada una de las lectoras una auto reflexión que les ayude a guiarse por los ideales que cada una quiere alcanzar.

En la actualidad muchas mujeres han asumido la responsabilidad de la libertad que poco a poco se les ha ido entregando, no se ha logrado del todo, es un proceso que ha llevado su tiempo y lo seguirá llevando, pues las costumbres son tan arraigadas que se vuelve difícil que se dé rápido la aceptación de una mujer independiente, llena de privilegios que le permitan estar bien, económica y físicamente. Algunas mujeres en nuestros días, son las que deciden por su cuerpo, desde cambios que le quieren hacer, 
como son las cirugías plásticas, que les permiten tener el cuerpo deseado, deciden cómo y en qué momento procrear, deciden si quieren llevar una relación emocional al matrimonio o simplemente quedar en unión libre, todo esto ha permitido que muchas mujeres dejen la opresión o depresión que les generaba el estar sujetas a los roles domésticos, entregadas por completo a los hijos y marido, que nunca tomaban la iniciativa de preguntarles si se sentían plenas o felices por lo que habían hecho con su vida.

\section{Conclusiones}

El pensamiento de Simone de Beauvoir, su filosofía feminista, su visión de independencia y libertad sigue siendo la meta para comprender que se ha llegado a un avance entre los roles de género. En la actualidad muchos temas han sido debatidos desde puntos feministas ya que hoy en día se encuentra la lucha constante entre la sociedad y la feminista radical, que es prejuiciada y a veces insultada por personas de su mismo género. No se ha entendido que el logro o la emancipación de la imposición del feminismo que se originada desde el siglo XVIII es la lucha colectiva, que integra todas las formas de vida de las mujeres, sin excluir a ninguna, ni ser superior al hombre, se ha buscado solamente la igualdad en todos los aspectos.

En base a la investigación de algunos artículos relacionados o especializados en esta filosofía feminista y en concreto de la obra El segundo sexo, muestran de manera paralela como se sigue teniendo la misma lucha constante, entre la sociedad y las leyes, los prejuicios y los límites que la moralidad o las tradiciones imponen.

De manera lineal y conforme los apartados que se han realizado en este trabajo, podemos concluir de forma parcial, que desde el primer apartado encontramos una revolución de lo que se quería lograr con las olas feministas, pues Simone de Beauvoir llega a expresar vivencias que ni las mismas mujeres eran capaz de trasmitir, pues bien, el hecho de lo sexual se volvía algo vergonzoso para todos. Concretamente en el apartado dos nos centramos en los puntos que señala y reflexiona Simone de Beauvoir, 
en los dos tomos de su obra El segundo sexo, pues en el primero se reseña la forma en que se ha estructurado el sistema en el que el hombre ha sido el encargado de escribir la historia, en el segundo se llega más concretamente a la conclusión de una mujer libre e independiente que se puede lograr siempre y cuando la mujer se responsabilice de los actos y no se sienta insegura en ningún aspecto. En el apartado tres se unen varias especialistas en el feminismo de Simone de Beauvoir para encontrar las respuestas que esta misma teoría ha encontrado con el paso del tiempo, la mujer debe situarse en el lugar que ella necesite para ser feliz y plena, pues muchas veces no sigue como necesaria una profesión u oficio, como hemos mencionado en el trabajo, la pluralidad de pensamiento otorga a que cada mujer siente de forma distinta una situación a otra, mientras unas son plenas en la independencia que de Beauvoir nos muestra, otras lo son desde las ocupaciones que tienen en el hogar.

La conclusión general del trabajo expone que es posible considerar la vigencia del pensamiento de Beauvoir en el feminismo contemporáneo, pues la idea de un sistema patriarcal sigue estando presente en cualquier lugar, que no pueda tolerar la capacidad y la integración cada vez más resaltante del sexo femenino en diversas áreas de trabajo.

Las diversas fuentes de consulta nos guiaron a identificar en que puntos ha sido recibida la propuesta de una mujer independiente de Beauvoir, al igual que considerar aspectos que necesitan de ser trabajados para una libertad en la mujer, muchas veces se piensa de forma distinta de lo que significa la libertad desde el enfoque feminista. El abordar este tema no es necesariamente que pienses en querer cambiar toda la situación de las mujeres, se analiza desde un enfoque personal, como las mujeres podemos hacer algo para ir cambiando las ideas machistas de poco a poco. 